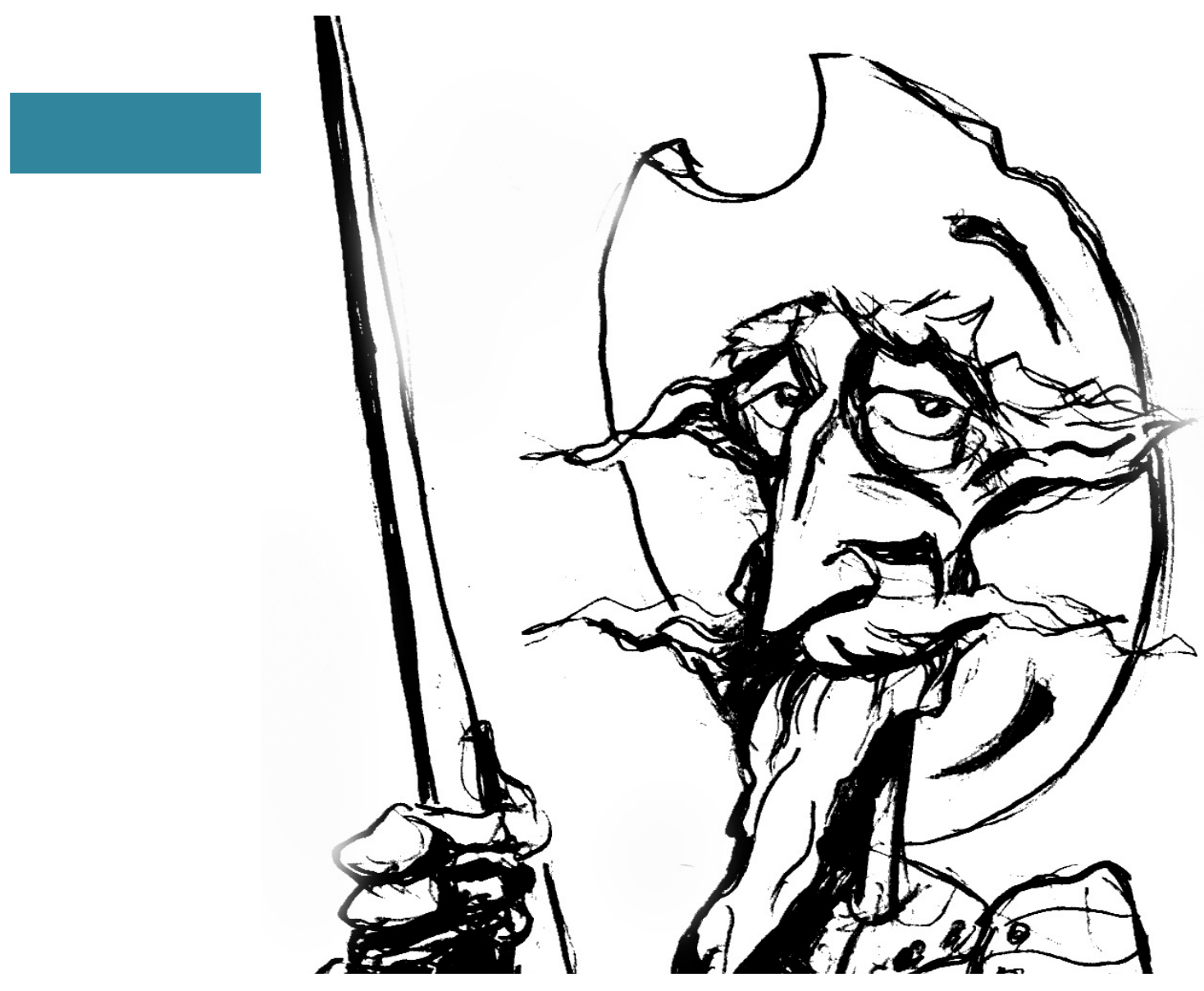

De aristócratas revolucionarios a vanguardia de clase. La revisión del peronismo en Tacuara y sus agrupaciones derivadas

[Esteban Campos] 



\title{
De aristócratas revolucionarios a vanguardia de clase. La revisión del peronismo en Tacuara y sus agrupaciones derivadas*
}

\author{
From Revolutionary Aristocrats to Class Vanguard. The Review of Peronism \\ in Tacuara and its Derivative Groupings
}

ESTEBAN CAMPOS

\begin{abstract}
Resumen
El propósito de este artículo es estudiar los cambios en la conceptualización del peronismo que experimentaron el Movimiento Nacionalista Tacuara, el Movimiento Nueva Argentina y el Movimiento Nacionalista Revolucionario Tacuara. Asimismo, se investiga la percepción que tenía cada grupo de su papel como vanguardia revolucionaria, y su lugar en el movimiento peronista. Para abordar este problema se analizarán varios periódicos como Tacuara. Vocero de la juventud nacionalista, Ofensiva, Barricada, Tacuara del manchón y Nueva Argentina. El planteo sugiere que la revisión del peronismo por Tacuara obedece tanto a cambios de coyuntura como a tendencias intrínsecas del movimiento nacionalista.
\end{abstract}

\section{Palabras clave}

Peronismo; vanguardia; nacionalismo; situación revisionista; masas peronistas

\begin{abstract}
The purpose of this article is to study the changes in the conceptualization of Peronism experienced by the Tacuara Nationalist Movement, the New Argentina Movement and the Tacuara Revolutionary Nationalist Movement. It also investigates each group's perception of its role as a revolutionary vanguard, and its place in the Peronist movement. To address this problem, several newspapers such as Tacuara. Speaker of the nationalist youth, Offensive, Barricade, Tacuara del manchón and New Argentina will be analyzed. The proposal suggests that the review of Peronism by Tacuara obeys both changes in the conjuncture and intrinsic tendencies of the nationalist movement.
\end{abstract}

Key Words

Peronism; vanguard; nationalism; revisionist situation; Peronist masses

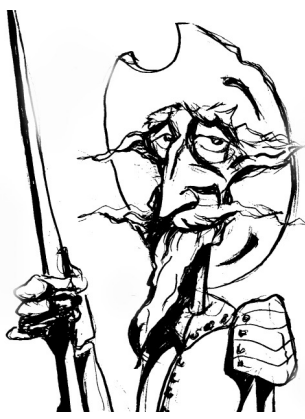

Recibido con pedido de publicación el 29 de marzo de 2019

Aceptado para su publicación el 10 de junio de 2019

Versión definitiva recibida el 5 de agosto de 2019

Esteban Campos, Consejo Nacional de Investigaciones Científicas y Técnicas, Universidad de Buenos Aires, Buenos Aires, Argentina; e-mail: estebancampos1977@gmail.com

\footnotetext{
* Agradezco los comentarios y sugerencias de los evaluadores de Revista Prohistoria

Esta obra se publica bajo licencia Creative Commons. Atribución-NoComercial-CompartirIgual $($ (c) EY-NC-SA 4.0 Internacional

Campos, Esteban "De aristócratas revolucionarios a vanguardia de clase. La revisión del peronismo en Tacuara y sus agrupaciones derivadas", Prohistoria, Año XXII, núm. 32, dic. 2019, pp. 155-181
} 
En los últimos meses de 1959, el periódico Tacuara. Vocero de la Juventud Nacionalista publicó una breve nota firmada por Alberto Ignacio Ezcurra Uriburu. El principal dirigente del Movimiento Nacionalista Tacuara (MNT) argumentaba allí que "la ortodoxia nacionalista tiene tanta vigencia hoy como hace treinta años". Este diagnóstico le permitía rechazar "una pretendida 'integración' en lo 'nacional y popular', de la cual participan socialistas, judíos, trotzkyistas, masones y marxistas de toda laya". ${ }^{1}$ Los tacuaristas querían conquistar el poder para impulsar la revolución nacional-sindicalista, y no iban alcanzar sus objetivos corriendo detrás de políticos como Juan Domingo Perón o Arturo Frondizi. En octubre de 1963, el Movimiento Nacionalista Revolucionario Tacuara (MNRT), que se había separado del MNT para definirse a favor de una revolución nacional y socialista, se posicionó desde un lugar diferente: "El peronismo por su sustrato humano es potencialmente el Movimiento Nacional Revolucionario, pero su acción se ve frenada por el aburguesamiento de un sector importante -por los resortes que tiene en su poder- de dirigentes". ${ }^{2}$ Dos años más tarde, el Movimiento Nueva Argentina (MNA), otro grupo escindido de Tacuara que proclamaba la revolución nacional justicialista, sostenía en su prensa que "Perón es único. Mientras viva, este Pueblo peronista le seguirá como el Jefe y le amará como Conductor y Caudillo". ${ }^{3}$

¿Qué había ocurrido en Tacuara y en el país para que de aquella organización madre surgieran desprendimientos con puntos de vista tan diversos? La situación revionista del hecho peronista tras el derrocamiento de Juan Domingo Perón, que planteó Carlos Altamirano en su obra clásica Peronismo y cultura de izquierda, también afectó a un sector de las derechas. Después de todo, como sostenía el político nacionalista Mario Amadeo, "El éxito o el fracaso del intento de unir al país depende, en buena medida, de cómo se interprete el hecho peronista" (Altamirano, 2001: 49-53). El propósito de este trabajo es estudiar los cambios en la conceptualización del peronismo que se dieron en el MNT, el MNA y el MNRT, y como estas interpretaciones se asociaron con la percepción que tenía cada grupo de su papel dirigente. Para cumplir este objetivo voy a analizar la prensa política de estas tres organizaciones procedentes del campo nacionalista, particularmente los números publicados entre 1959 y 1966 de Tacuara. Vocero de la juventud nacionalista, Ofensiva, Barricada, Tacuara del manchón y Nueva Argentina.

\footnotetext{
${ }^{1}$ Ezcurra, Alberto (1959) “Ortodoxia”, Tacuara. Vocero de la Juventud Nacionalista, Año XIV, núm. 7.

2 Baxter, Joe (1963) "Tacuara y la liberación nacional", Tacuara. Órgano del Movimiento Revolucionario Tacuara, núm.1 (octubre, primera quincena).

3 “Perón Jefe”, Nueva Argentina. Órgano del M.N.A. núm. 13 (noviembre de 1965), p. 2.
} 
Tacuara fue una organización nacionalista católica, que consiguió una importante repercusión pública entre 1958 y 1964, por sus prácticas antisemitas y anticomunistas. Sus orígenes se remontan a un puñado de militantes provenientes de la Unión Nacionalista de Estudiantes Secundarios, que participaron como comandos civiles en la Revolución Libertadora. ${ }^{4}$ La ideología del MNT se remontaba principalmente al horizonte cultural de la derecha argentina y europea de entreguerras: el falangismo de José Antonio Primo de Rivera, el nacional-sindicalismo de Ramiro Ledesma Ramos, el revisionismo histórico de Ernesto Palacio, José María Rosa y Fermín Chávez, el antisemitismo del padre Julio Meinvielle y el comunitarismo de Jacques-Marie de Mahieu, un intelectual francés con simpatías nazis que criticaba la propiedad privada y la plusvalía. En palabras de Ezcurra Uriburu, los tacuaristas no eran de izquierda ni de derecha, sino una síntesis superadora de ambas corrientes. ${ }^{5}$

A partir de la intervención en el conflicto conocido como laica o libre a favor de la legalización de las universidades católicas, el MNT creció en número y amplió su composición social. El núcleo originario, vinculado a jóvenes de familias patricias que predicaban un nacionalismo político y cultural, fue desbordado por la llegada de nuevos militantes más preocupados por la cuestión social, de perfil plebeyo y afinidades peronistas, lo que terminó por provocar una implosión. En octubre de 1960, un grupo cercano al padre Meinvielle, disgustado por la creciente influencia de Mahieu, se separó para fundar la Guardia Restauradora Nacionalista, denunciando que Tacuara había sido conquistada por el fidelismo, el trotskismo y el ateísmo (Padrón, 2017: 155170). En junio de 1961, siete activistas liderados por Dardo Cabo y Edmundo Calabro rompieron con Ezcurra Uriburu para crear el Movimiento Nueva Argentina, que se definió como parte del movimiento peronista y se acercó a sindicalistas como José Alonso y Augusto Timoteo Vandor (Bardini, 2002: 5765). Como se puede notar a través del análisis de su prensa, el MNA empleó un discurso nacionalista cuyas notas más estridentes eran el justicialismo, el anticomunismo y el antisionismo, aunque la labor de sus militantes alcanzó notoriedad por vías más directas: en agosto de 1964, un comando del MNA interrumpió con disparos y bombas de estruendo una cena en homenaje al ex presidente Frondizi, atentado que generó un acalorado debate en el Congreso Nacional (Ruffini, 2016). Un año más tarde, varios miembros del MNA formaron parte de la custodia de Isabel Perón en su visita a la Argentina, pero la

4 La Unión Nacionalista de Estudiantes Secundarios nació en 1935 como brazo juvenil de la Legión Cívica, el movimiento de inspiración fascista creado durante la dictadura de José Félix Uriburu. El crecimiento de la UNES llevó al lanzamiento de la Alianza de la Juventud Nacionalista en 1937, que más tarde se convirtió en la Alianza Libertadora Nacionalista. Hacia 1946 la ALN se acercó al peronismo, pero el enfrentamiento de Perón con la Iglesia católica terminó por fracturar la organización: mientras los aliancistas se convirtieron en un grupo de choque contra la oposición, la UNES se sumó al campo antiperonista (Furman, 2014).

5 “Los tacuaristas no somos asesinos, afirma su jefe". Crónica, 04/05/64. 
acción más audaz que protagonizaron fue el Operativo Cóndor de septiembre de 1966. Pocos meses después del golpe de estado encabezado por Juan Carlos Onganía, un grupo armado en el que se encontraban militantes del MNA como Dardo Cabo, Andrés Castillo y Alejandro Giovenco secuestro un avión comercial y lo desvió hacia las Islas Malvinas, donde se desplegaron varias banderas argentinas.

En diciembre de 1962 tuvo lugar la ruptura del Movimiento Nacionalista Revolucionario Tacuara, a partir de un grupo liderado por José Luis Nell, Joe Baxter y Alfredo Ossorio, que elaboró un discurso nacionalista más permeable a la cultura de izquierdas. El MNRT se definía peronista y revolucionario, proclamaba la revolución nacional y socialista, se identificaba con la Revolución argelina y concebía a la lucha armada como el principal método para la toma del poder. Esta mutación expresaba el pasaje de la ideología nacional-católica del MNT, caracterizada por una teología política en clave racialista, a un nacionalismo más secularizado, interesado por la emancipación económica y social del Tercer Mundo (Campos, en prensa). Al poco tiempo, Ossorio y sus seguidores cuestionaron lo que entendían como un giro a la izquierda del sector de Baxter y Nell, que había renegado del antisemitismo y tenía contactos con marxistas como Ismael Viñas, Ricardo Rojo y Mario Valotta (Gutman, 2003: 155156). El MNRT-Ossorio se agrupó en torno al periódico Barricada, que conservó algunos tópicos racialistas con un discurso próximo a las ideas comunitarias de Mahieu, mientras que el grupo conducido por Baxter y Nell optó por publicar su propio órgano de prensa. ${ }^{6}$ En agosto de 1963, la fracción izquierdista del MNRT asaltó el Policlínico Bancario del barrio porteño de Caballito con un saldo de dos muertos, tres heridos y un botín equivalente a 100.000 dólares, pero al año siguiente una investigación policial llevó a una ola de arrestos que disolvió la organización. En la cárcel, varios militantes tacuaristas se acercaron al marxismo, sin abandonar el peronismo como identidad política. Algunos, como Jorge Caffatti, Carlos Arbelos y Alfredo Roca, continuaron su militancia en las Fuerzas Armadas Peronistas. Otros, como Joe Baxter y José Luis Nell, se vincularon al Ejército Revolucionario del Pueblo y a Montoneros, respectivamente.

Desde su emergencia en la década del '40, el peronismo generó profundas tensiones en el campo nacionalista. Algunos se entusiasmaron con un movimiento apoyado por la Iglesia católica y la Fuerzas Armadas, que parecía realizar el sueño de un gobierno autoritario, soberanista y antiliberal.

\footnotetext{
6 Tacuara. Vocero de la juventud nacionalista era la prensa oficial del MNT, mientras que Ofensiva fue un boletín interno de la misma organización, que dependía del Departamento de Formación. Barricada y Tacuara. Órgano del Movimiento Nacionalista Revolucionario Tacuara (también conocido como Tacuara del Manchón) eran los periódicos del MNRT, que respondían respectivamente al sector Ossorio y al sector Baxter-Nell. Por último, Nueva Argentina fue el órgano de prensa del Movimiento Nueva Argentina.
} 
Otros desconfiaban de la base plebeya y las ambigüedades ideológicas del coronel Perón, al que consideraban un demagogo plagiario del discurso nacionalista. Hacia 1954, las diferencias del nacionalismo en torno al fenómeno peronista se convirtieron en enemistad abierta, cuando el conflicto entre el gobierno justicialista y la Iglesia encontró a la ALN y la UNES en bandos opuestos. La distensión de la rígida polarización entre peronistas y antiperonistas tras el golpe militar de 1955 permitió, como resultado de la persecución a los partidarios del gobierno depuesto, una mayor fluidez de las identidades políticas y las trayectorias militantes. En algunos sectores de la derecha nacionalista, el centro demócrata y la izquierda marxista, el fenómeno peronista empezó a ser revalorizado, en parte por su arraigo como identidad popular, en parte debido a la ambición por apoderarse de un capital político a primera vista vacante por la ausencia del máximo líder.

En los últimos años, varias investigaciones han abordado el problema de las relaciones entre Tacuara y el movimiento peronista. Valeria Galván sostiene que la influencia del peronismo en el grupo de Ezcurra Uriburu fue exagerada por la historiografía especializada y por la opinión pública de su tiempo. El MNT veía al peronismo como un nacionalismo imperfecto, y el acercamiento del primero al segundo no tendría que ver únicamente con un cambio en la composición social de la organización, sino con las coincidencias entre las ideas nacional-sindicales y el justicialismo. En consecuencia, los desgajamientos de militantes de Tacuara hacia el peronismo serían una extensión de la militancia por los ideales nacionalistas (Galván, 2013). Más allá de estas continuidades, en la diáspora del MNT se formaron nuevas organizaciones y en el caso del MNRT, se marginaron tópicos como el racialismo, el catolicismo y el nacionalismo político-cultural para incorporar otros, como el clasismo y el nacionalismo económico. En este proceso, el peronismo contribuyó a la crisis y división de Tacuara, de manera similar al proceso de descomposición sufrido por la ALN en los años '40 y '50. Como apunta Daniel Lvovich, la expansión del peronismo y su eficacia para "articular alas de signos políticos contradictorios, dejaban poco margen para un accionar autónomo que permitiera el crecimiento de la derecha nacionalista" (Lvovich, 2009: 45-61). Para Michael Goebel, el peronismo fue una esfera de sociabilidad que enlazó a militantes provenientes de la derecha y la izquierda, y la peronización jugo allí un papel clave como "activador decisivo de la movilidad ideológica", con el antiimperialismo como denominador común (Goebel, 2007). Finalmente, historiadores como Juan Manuel Padrón y Juan Luis Besoky consideran que el creciente interés del MNT por la cuestión social alrededor de 1960 -visible por la incorporación a su discurso de conceptos aportados por Mahieu- fue paralelo al acercamiento al peronismo, experiencia que tuvo hitos como la participación de militantes tacuaristas en la toma del frigorífico Lisandro de la Torre (Padrón, 2017: 159163; Besoky, 2016: 110-141). El repertorio de actores peronistas que convergieron 
con Tacuara fue muy heterogéneo, desde dirigentes de la Juventud Peronista como Envar El Kadri y figuras del primer peronismo como Alberto Ottalagano, hasta las diferentes corrientes sindicales de la CGT.

\section{La Tacuara nacionalista y el peronismo: golpear juntos, marchar separados}

Desde 1930, el nacionalismo argentino tuvo dos maneras de percibir la relación entre las masas y las élites; la primera veía a las minorías como el motor de la historia, en contraste con unas mayorías carentes de iniciativa. La segunda se planteó convertir al nacionalismo en un movimiento de masas, lo que impulsó la incorporación de demandas populares y la difusión de conceptos como el de justicia social (Lvovich, 2006: 52-56). Tacuara también osciló entre las dos tendencias, pero en varias ocasiones enfatizó las diferencias entre la élite revolucionaria y unas masas caracterizadas como pasivas e irracionales:

“No creemos en la 'revolución de masas'. La Revolución exige doctrina y organización. La masa es instintiva e inorgánica. La Revolución es un proceso activo, la masa es un elemento pasivo [...] En la mayor parte de los hombres prima el egoísmo individualista (característica esencial del burgués) sobre el sentido del deber social. Aquellos que por este deber, por un ideal, están dispuestos a vivir, a jugarse, a sacrificarse, forman una minoría reducida, pero es el único sector dinámico capaz de producir transformaciones sociales. TACUARA busca encuadrar en sus filas a estos hombres, obreros, estudiantes, militares, profesionales, para formar con ellos la auténtica aristocracia revolucionaria, milicia que nos dará la Nación que hoy no tenemos, pero que existe como posibilidad magnífica del futuro." 7

La denigración de las mayorías era un lugar común del discurso antidemocrático que desarrolló el nacionalismo de derechas en el período de entreguerras, tanto en Argentina como en Europa. Como señala Zeev Sternhell, en los orígenes del fascismo italiano había una conexión entre "las inertes y desorganizadas masas, la ley de los números y la democracia, y su culto de las minorías, la violencia y la acción directa" (Sternhell, Snajder y Asheri, 1994: 243). ${ }^{8}$ La aristocracia revolucionaria no era algo dado a priori, ya que "la Revolución solo puede ser llevada a cabo por una minoría orgánica y

\footnotetext{
7 "Aristocracia Revolucionaria" (s/f), en Tacuara. Vocero de la juventud nacionalista. Año XVIII, s/n (c. diciembre 1963), p. 3.

8 Por otro lado, Adolfo Hitler indicaba que “La gran mayoría del pueblo es, por naturaleza y criterio, de índole tan femenina, que su modo de pensar y obrar se subordina más a la sensibilidad anímica que a la reflexión", Mi lucha, capítulo 6, "Propaganda de guerra", p. 53, en https://espacioculturayarte.wordpress.com/2015/07/02/mein-kampf-mi-lucha-adolf-hitler-pdf/
} 
adoctrinada, seleccionada por el proceso natural de decantación que se da en la lucha". ${ }^{9}$ La aclaración recuerda a la teoría de la organización-proceso en Rosa Luxemburgo, con la primera salvedad de que el marxismo, a diferencia del nacionalismo de derechas, reconocía a la lucha de clases como el motor de la historia. ${ }^{10}$ Desde luego, la idea de que la vanguardia nacionalista debía surgir del propio proceso de lucha no equivalía a una reivindicación del espontaneísmo:

"Nuestra consigna sigue siendo ORGANIZACION PARA LA REVOLUCION inevitable. Hay que avivar el rescoldo, despertar las reservas dormidas de nuestro pueblo, formar con los mejores hombres de la juventud, del sindicalismo, del ejército, una auténtica aristocracia revolucionaria. El nacionalismo debe organizarse. Barrer de sus filas a los que aún no han roto el cordón umbilical que los une con la democracia burguesa. Formar las escuadras de asalto para el día del derrumbe."11

Esta idea "leninista" de la organización, que requería preparación, profesionalismo y selectividad para actuar en tiempos de crisis como grupo dirigente, requería adelantarse al comunismo en la carrera por destruir al régimen liberal. El llamado a purgar el nacionalismo de cualquier figura que tuviera compromisos con la democracia burguesa, bien podía apuntar a políticos como Mario Amadeo, Raúl Puigbó, Mariano Montemayor y Bonifacio Lastra, que apoyaron el proyecto desarrollista de Frondizi desde la derecha nacionalista (Beraza, 2005: 110-120). La aristocracia revolucionaria tacuarista, en cambio, debía ser capaz de darle una orientación transformadora al movimiento de masas, razón por la cual su política hacia el peronismo osciló entre la cautela y la cooptación. En septiembre de 1961, el MNT publicó una nota en solidaridad con la Juventud Peronista, donde encomiaba su sacrificio militante, sus presos y sus muertos en la lucha contra la proscripción. Sin embargo, el texto también establecía una clara distinción entre Perón y los jóvenes militantes del movimiento:

“Esta juventud está muy lejos de la prebenda fácil, del pancho,

\footnotetext{
9 "Aristocracia revolucionaria", cit., p. 3.

${ }^{10}$ Luxemburgo, Rosa (1904). "Problemas organizativos de la socialdemocracia", disponible en URL:

https://www.marxists.org/espanol/luxem/04Problemasorganizativosdelasocialdemocracia 0.pdf . Para una evaluación crítica, v. Bensaid, Daniel y Nair, Samy "Lenin y Rosa Luxemburgo", disponible en URL: http://danielbensaid.org/Lenin-y-Rosa-Luxemburgo?lang=frpp pp. 20-26. La concurrencia de estas ideas sobre el rol de la organización no permite pensar que existan conexiones entre la teoría de Rosa Luxemburgo y la formación intelectual de los jóvenes tacuaristas, que ya hemos repasado en la primera parte del artículo.

11 Tacuara, “Comenzó la 'Illiada'”, en Tacuara. Vocero de la juventud nacionalista. Año XVIII, s/n (noviembre 1963), p. 1.
} 
la coca-cola y la motoneta. Levanta nuestras mismas banderas, para defenderlas con un sentido heroico de la vida. Frente a los hechos, no vamos a discutir nosotros si esas banderas se encarnan o no en un hombre o en un nombre [...] No es hora de discutir nimiedades, de resucitar rencores viejos, sino de redimir esa sangre y de quebrar esas rejas. Nos veremos en la misma trinchera, para la Reconquista Nacional." ${ }^{12}$

La crítica a Perón como un demagogo frívolo, que atraía a sus seguidores con prácticas clientelares, repetía los lugares comunes del antiperonismo de las clases medias y altas. Pero al mismo tiempo, Tacuara intentaba tender un puente hacia las bases peronistas cuidándose de "resucitar rencores viejos", un discurso en línea con el efímero lonardismo de los militantes unistas que habían fundado el MNT (Goebel, 2007: 362; Gutman, 2003: 42-44; 62-64). ${ }^{13}$ Dos años más tarde, en "La crisis del sindicalismo", Ezcurra Uriburu lanzó sus dardos contra la "burocracia de dirigentes muchas veces sin representación real", que era funcional a una mayoría trabajadora con mentalidad burguesa. ${ }^{14} \mathrm{Si}$ bien en ninguna parte del artículo se reconocía la identidad peronista de gran parte de los sindicalistas, hacia el final el jefe tacuarista llamaba a "infundir al sindicalismo una conciencia revolucionaria, de modo que los objetivos inmediatos de la lucha no le hagan perder de vista el sentido mediato de la misma hacia el objetivo final al que nos hemos referido: la integración comunitaria del proletariado". ${ }^{15} \mathrm{La}$ voluntad de trasplantar al cuerpo peronista una cabeza orientada al cambio radical, era concurrente con la ansiedad de los católicos, izquierdistas y nacionalistas que pretendían revolucionar el justicialismo en los años '60.

En el boletín interno Ofensiva de noviembre de 1962, Ezcurra Uriburu publicó un duro escrito titulado "La crisis del peronismo". Según el principal dirigente del MNT, la anulación de las elecciones provinciales del 18 de marzo por el ex presidente Frondizi, obligaba a una "profunda revisión táctica, histórica y doctrinaria" del justicialismo, sin capacidad de respuesta por la "carencia de cuadros revolucionarios, producto de la vaguedad doctrinaria y

12 M.N.T., "Solidaridad", en Tacuara. Vocero de la juventud nacionalista. Año XVI, núm. 10 (septiembre 1961).

13 Sobre el lonardismo de Tacuara, Laura Ehrlich cita un testimonio muy ilustrativo de G.B.: "El Instituto Histórico Juan Manuel de Rosas estaba en manos de los nacionalistas, nacionalistas católicos, y había muchos gorilas, y ahí iban los chicos de Tacuara. Los chicos de Tacuara cuando salían, gritaban 'San Martín, Rosas, Lonardi' y nosotros gritábamos 'San Martín Rosas Perón' y ahí los 'cagábamos' a palos, yo inclusive les tiré unos tiros ahí", v. Ehrlich, Laura (2010). Rebeldes, intransigentes y duros en el activismo peronista, 1955-1962, tesis de maestría en Ciencias Sociales, Universidad Nacional de General Sarmiento, p. 101.

14 Ezcurra, Alberto (noviembre 1963). "La crisis del sindicalismo", en Tacuara. Vocero de la juventud nacionalista. Año XVIII, s/n, p. 3.

15 Ezcurra, Alberto (noviembre 1963). "La crisis...", cit., p. 3. Las cursivas figuran en el original. 
del lastre burgués que frustró al peronismo en el poder". ${ }^{16}$ Lo único que garantizaba la unidad del movimiento proscripto era la figura de Perón, por eso Ezcurra Uriburu se apresuraba a profetizar que tras la desaparición de su líder, el peronismo tendería inexorablemente hacia el nacionalismo o el marxismo. Más allá del número de sus simpatizantes, "el Movimiento peronista no existe como unidad orgánica, sino como una variedad de fuerzas endeblemente coordinadas cuando no antagónicas" ${ }^{17}$ El balance final era lapidario, y se condensaba en una de las metáforas más inspiradas del jefe tacuarista:

"El peronismo se nos presenta como un inmenso flan que influye en la vida nacional por el solo peso muerto de su expresión numérica. Se trata de un gran potencial revolucionario, de una masa con sentido nacional, pero su permanencia a la deriva, como fuerza muerta, en actitud de resistencia nostálgica y pasiva, puede convertirlo en un factor retardador y disociante de todo intento de solución nacional revolucionaria, pues el peor enemigo de la Revolución no es quien abiertamente la combate, sino el que la proclama y quiere capitalizarla, pero es incapaz de llevarla a cabo." 18

Si consideramos las definiciones del peronismo de manera transversal a las formaciones militantes y las ideologías políticas, ¿la metáfora del flan no es similar al juicio que hacía John William Cooke del peronismo como un "gigante invertebrado y miope", incapaz de transformar el número en fuerza? De manera recurrente, las multitudes peronistas eran vistas como una materia prima, masas en disponibilidad a la espera de ser moldeadas por la vanguardia revolucionaria. ${ }^{19}$

La idea que Tacuara tenía del peronismo no era homogénea ni monolítica. En el mismo número de Ofensiva donde se publicó “La crisis del peronismo", Oscar Denovi señalaba que "periódicamente algunos grupos de nacionalistas son acometidos por pujas de captación". ${ }^{20}$ La infiltración de fuerzas políticas era una tarea que requería paciencia, meticulosidad y recursos, como demostraba el ejemplo a seguir del Partido Comunista. En cambio, el nacionalismo "se entregó con inconsciencia infantil o se rindió sin honor [...] perdió de inmediato el dominio de los acontecimientos y se confundió con la

16 Ezcurra, Alberto (noviembre 1962). "La crisis del peronismo", en Ofensiva, núm. 11, pp. 3-4.

17 Ezcurra, Alberto I. "La crisis...", cit., p. 3.

18 Ezcurra, Alberto I. "La crisis...", cit., p. 4.

19 "Universidad y país". Conferencia de John William Cooke. Córdoba, 4 de Diciembre de 1964", (Baschetti, 1997: 350-386) y Cooke, John William (octubre-noviembre 1966). "Definiciones", en Cristianismo y Revolución, nro. 2-3, pp. 5-6. Disponible en URL: http://eltopoblindado.com/agrupaciones/publicaciones-afines/cristianismo-y-revolucion/

20 Denovi, Oscar (noviembre 1962). “Tacuara y la técnica de la infiltración”, en Ofensiva, núm. 11, pp. 7-9. 
masa vil, indiferenciada". ${ }^{21}$ Por si quedaba alguna duda, en el último tramo del artículo Denovi se refiere explícitamente a las relaciones entre el MNT y el movimiento peronista: “El ingreso de Tacuara en la legión de especuladores y agiotistas del peronismo, con el inevitable regateo de gitanos que ello supone, ¿no significaría la pérdida de autenticidad y la renuncia, quizá definitiva, a los derechos de primogenitura a la Revolución Nacional?".22 Para el autor era fundamental preservar la autenticidad y la pureza identitaria de la organización, ya que existía un elevado riesgo de mestizaje con la fuerza que se intentaba cooptar. Aunque esta opinión se correspondía con la línea política elaborada por la jefatura tacuarista, el diagnóstico sobre el peronismo era sensiblemente diferente al de Ezcurra Uriburu: “...el peronismo no es una presa fácil. Tiene su historia, sus cuadros, su doctrina, sus mártires y su caudillo. La misión, queda dicho, consiste en un trato leal y en un intercambio sincero con la corriente nacional y católica que actúa en ese medio. Entiéndase bien: colaboración y no capitulación. ${ }^{23}$

En este balance no había debilidades doctrinarias ni falta de liderazgo, si no una evaluación más cautelosa de la magnitud de las fuerzas peronistas a fines de 1962. Además, el texto se hacía eco de las tensiones que concluirían con la fractura del MNRT, ya que Denovi advertía sin eufemismos que: "Es hora, también, de poner en vereda a los impacientes y a los díscolos". ${ }^{24}$ A fines de 1963, Pedro Otaño escribió para el boletín Ofensiva una nota que planteaba el copamiento de las 62 organizaciones peronistas por el comunismo. Las primeras señales de esta tendencia se habrían dado, según el autor, por "el inexplicable silencio guardado sobre el asunto Eichmann", "el tono marxistoide de discursos y documentos de esa tendencia", y la presencia de la CGT en el Luna Park al conmemorarse un aniversario del levantamiento del ghetto de Varsovia, entre otras actitudes que evidenciarían "el dominio que la fracción trotzkysta ejerce en el seno de la agrupación". ${ }^{25}$ Sin embargo, la piedra del escándalo había sido la declaración cegetista de julio de 1963 en contra del decreto que reprimía las actividades comunistas. Lo que más indignaba a Otaño era la crítica del documento sindical el carácter "fundamentalmente fascistizante" de la medida, lo que le permitía a continuación ofrecer su propia caracterización del peronismo:

"A esta altura del avance marxista carece de sentido seguir fingiendo que allí nada pasa y que las 62 organizaciones siguen siendo el puntal de la revolución nacional. Siempre sostuvimos que el peronismo carecía de doctrina, que sus hombres

\footnotetext{
21 Denovi, Oscar (noviembre 1962). "Tacuara...”, cit., pp.7-8.

22 Denovi, Oscar (noviembre 1962). "Tacuara...", cit., p. 8.

23 Denovi, Oscar (noviembre 1962). "Tacuara...", cit., p. 9.

24 Denovi, Oscar (noviembre 1962). "Tacuara...", cit., p. 9.

25 Otaño, Pedro (c. segunda mitad de 1963). "Fagocitosis al revés”, en Ofensiva s/f, pp. 4-6.
} 
respondían a tendencias diversas y que su unidad descansaba precariamente sobre la base de un efímero mito. Pero también creímos y seguimos creyendo, a pesar de todo, que allí existen tendencias nacionales capaces de armonizar en un gran movimiento de salvación pública." 26

La definición repite los principales tópicos de la dirigencia tacuarista pero, considerada en el conjunto del texto, llama la atención porque carece del optimismo y la firmeza de la anterior posición de Tacuara, que tenía la expectativa de poder cooptar a las bases peronistas. Aquí el peronismo, a pesar de su falta de doctrina y coordinación, no parece el patético flan de Ezcurra Uriburu. ¿Qué había ocurrido con Tacuara? Por la cita del decreto del presidente Guido, se puede deducir que el texto de Otaño fue publicado durante o después de producirse la ruptura de Baxter, Nell y Ossorio, que terminó por relegar al MNT a una creciente marginalidad, en buena medida porque los cooptadores se convirtieron en cooptados. Con la renuncia de Ezcurra Uriburu a la jefatura en 1964, la Tacuara dirigida por Juan Mario Collins no renegó de sus vínculos con el peronismo, y se consolidó como un grupo periférico de la derecha sindical (Glück, 2012). Si pensamos en la coyuntura internacional, efectivamente el mundo parecía girar a la izquierda, mientras el modelo insurreccional de las revoluciones tercermundistas seducía a segmentos cada vez mayores de las juventudes militantes argentinas. No obstante, el Movimiento Nueva Argentina se empecinó en escribir su propia historia al margen de estas tendencias.

\title{
El Movimiento Nueva Argentina: una milicia para servir a Perón
}

\author{
Somos una generación que marcha \\ sobre los escombros del régimen \\ caduco para plasmar la \\ arquitectura revolucionaria de una \\ Nueva Argentina justa libre y \\ soberana
}

Proclama del MNA

En una fecha indeterminada que se puede ubicar entre mediados de $1961 \mathrm{y}$ comienzos de 1962, un periodista de la revista Vea y Lea entrevistó al MNA. Como los editores finalmente tomaron la decisión de no difundir el reportaje, la agrupación liderada por Dardo Cabo decidió publicarla por su cuenta como

\footnotetext{
26 Otaño, Pedro (c. segunda mitad de 1963). "Fagocitosis...", cit., p. 4.
} 
folleto. En el documento, los militantes emeneistas describían a la Revolución Nacional Justicialista como aquella que reunía al pueblo argentino sin distinción de individuos, clases y partidos, por lo tanto opuesta a la "acción deformadora de las internacionales, sin credo, sin bandera, que hoy nos sojuzgan". ${ }^{27}$ El MNA era anticapitalista en la medida que consideraba al capitalismo un sistema de explotación contrario a la naturaleza humana. Como indicaba una proclama de octubre de 1961, la revolución nacional debía establecer un nuevo orden social:

"En el que el trabajador sea propietario directo de los bienes de producción, que constituyen el medio para el logro de sus fines. Solo así se acabará con la explotación del hombre por el hombre, dramática realidad del régimen capitalista que desemboca inevitablemente en el marxismo apátrida, reaccionario y ateo." 28

Estas primeras definiciones del MNA eran enteramente compatibles con el concepto de justicia social redistributiva del peronismo, que se desarrolló sobre todo en las columnas del periódico Nueva Argentina, órgano de prensa oficial de la agrupación. A diferencia de las concepciones de la Tacuara de Ezcurra Uriburu, para el MNA el peronismo era el gran movimiento nacionalista argentino. Como señalaban sus militantes en el reportaje de Vea $y$ lea, las fracciones del nacionalismo que habían reconocido en el peronismo una opción revolucionaria constituían su vanguardia:

“7.-) ¿Consideran que el nacionalismo es una elite llamada a
gobernar?
R.- El 17 de octubre de 1945, el nacionalismo dejó de ser una
elite para convertirse en la vanguardia de un gran movimiento
popular. Eso somos nosotros: vanguardia. Los que en el 45
prefirieron conservarse en situación de "minorías selectas y
puras", han acabado en expresiones lamentables de
claudicación, cayendo en posiciones liberales o marxistas. Son
ineptos para conducir a un país que no comprenden."

En efecto, el MNA se consideraba a sí mismo como "la avanzada del movimiento social más formidable de este siglo". ${ }^{30}$ Sin embargo, estas nociones no eran equivalentes a la idea de una vanguardia de clase. En el artículo "El

\footnotetext{
27 "Reportaje al MNA" (s/f), p. 1. Disponible en URL: http://eltopoblindado.com/nacionalismoderecha/decada-1960-nacionalismo-derecha/movimiento-nueva-argentina/reportaje-al-mna/

28 "Proclama Movimiento Nueva Argentina" (octubre de 1961), p. 2. Disponible en URL: http://eltopoblindado.com/nacionalismo-derecha/decada-1960-nacionalismoderecha/movimiento-nueva-argentina/mna-proclama/.

29 "Reportaje...", cit., p. 2.

30 "Reportaje...", cit., p. 2.
} 
golpe y la integración", publicada por Nueva Argentina en julio de 1965, la prensa emeneista acusó al presidente Arturo Illia de pretender integrar el peronismo al sistema, lo que exigía una política más firme del justicialismo frente al gobierno y la bancada radical en el Parlamento. La afirmación es interesante, ya que carece de los tópicos antiliberales que rechazaban de plano el sistema de partidos en Tacuara, puesto que reconocía implícitamente la legitimidad de los parlamentarios neoperonistas en el Congreso Nacional. Si para ese momento el MNA era financiado por un empresario cercano al vandorismo, la organización de Dardo Cabo sostenía de manera solemne "que Peronismo hay uno solo y que el Peronismo tiene un Jefe, autoridad indiscutible y que cualquier acuerdo que planeen no tendrá sentido alguno si no lleva el visto bueno de Perón". ${ }^{31}$ En el número 13 de Nueva Argentina, las declaraciones de lealtad ya configuran un auténtico culto a la personalidad del líder justicialista:

"Perón no es símbolo. Perón no es bronce. Perón es Jefe auténtico y real. Único Jefe del Movimiento Nacional Justicialista. Su presencia no es sólo el factor aglutinante, sino que por antonomasia es conductor de este Pueblo que lo ha elegido para cumplir los destinos de gloria del Movimiento Nacional que son los destinos de la Patria y del Pueblo mismos. Perón es caudillo." ${ }^{32}$

Esta definición del líder en el exilio se diferenciaba claramente de la caracterización que hacía la prensa tacuarista de Perón como un nombre (un vacuo signo cuyo referente se encontraba a miles de kilómetros), un mito con fecha de vencimiento, o un simple dirigente de carne y hueso que sólo servía para garantizar la unidad del movimiento. Desde el punto de vista del MNA, Perón no era un frío y venerable monumento, sino un caudillo investido de todas las cualidades del liderazgo carismático:

"Pocos hombres se han dado en la historia, que por su relevancia, su don natural, casi divino, han llegado a conducir a los pueblos. Pareciera que en ellos Dios y la historia posaran su mano, para que en un lugar y tiempo determinados, marcarlos con el fuego divino que alimenta a los hombres y les hace acercarse a ellos para entregarse a luchar por una causa de justicia. Esos hombres son irreemplazables. Su molde se rompe y su lugar es tan único, que nadie puede ocuparlo. No dejan herederos de sus virtudes. Tampoco se las llevan consigo, pues

31 “El golpe y la integración” (s/f), en Nueva Argentina, núm. 10 (julio 1965), p. 3. Desde 1965, el MNA recibió aportes del empresario César Cao Saravia, cercano a la Unión Obrera Metalúrgica (Bardini, 2002: 59).

32 "Perón jefe" (s/f), en Nueva Argentina, núm. 13 (noviembre 1965), p. 2. Los fragmentos figuran en cursiva en el original. 
las entregan al Pueblo cuando Dios, cumplida su misión, los llama a su diestra." 33

A pesar del manifiesto verticalismo del MNA, las últimas líneas de este pasaje podrían dejar entrever un deseo de obtener, como vanguardia del pueblo peronista, ese carisma aparentemente intransferible. Pero los militantes emeneistas se consideraban una milicia al servicio del máximo jefe del justicialismo, y se ubicaban, al menos en sus declaraciones públicas, como un sector claramente subordinado al liderazgo de Perón: “Los jóvenes de este movimiento, quienes tratamos de alumbrarnos con su fuego, quienes como "Nueva Argentina" somos su milicia damos el presente como soldados a este glorioso Jefe. No dejaremos jamás de darlo y cuando nuestra voz no se escuche será porque estaremos ocupando el lugar que en la eternidad nos corresponda." 34

En otro artículo publicado en el mismo número de Nueva Argentina, se especificaba cual era la función de la milicia peronista. El texto explica de qué manera el peronismo se había formado con la concurrencia de sectores políticos y sociales enfrentados hasta la aparición de Perón en el escenario político. Poco a poco, las viejas ideas liberales fueron reemplazadas por la Doctrina Nacional Justicialista, pero aunque el líder del movimiento hablaba frente a auditorios multitudinarios con una estrategia de comunicación directa, "los intermediarios en el peronismo eran -y aún lo son-, en su gran mayoría, la 'resaca' del régimen caduco". ${ }^{35}$ La milicia, en cambio, formaba parte junto al conductor y a la doctrina de las bases de cualquier revolución; en palabras del propio MNA, esta particular forma de la vanguardia era:

"El grupo compenetrado espiritual e intelectualmente, al extremo de darlo todo sin pedir nada en un acto de servicio. Un grupo de hombres hechos a idea y semejanza del Conductor, poseídos por el sentimiento de lealtad y la idea de la realización revolucionaria. Un grupo intolerante en todo lo que afecte a los objetivos del Movimiento, INTOLERANTE CON LOS TRÁNSFUGAS, CON LOS INFILTRADOS, CON LOS DESVIADOS." 36

La milicia no quería ser conducción, porque la conducción era Perón, de allí que estas declaraciones fueran más bien ajenas a la estrategia tacuarista de cooptar al peronismo. En el MNA había una cultura política ampliamente compartida que amalgamaba el nacionalismo y el peronismo, con un discurso

\footnotetext{
33 "Perón...", cit., p. 2.

34 "Perón...", cit., p. 2.

35 "La función de la milicia" (s/f), en Nueva Argentina núm. 13 (noviembre 1965), p. 2.

36 "La función de la milicia" (s/f), en Nueva Argentina núm. 13 (noviembre 1965), p. 2. Los fragmentos con letra mayúscula aparecen en el original.
} 
destinado al control de las disidencias internas que alcanzaría una amplia difusión en los enfrentamientos entre la derecha y la izquierda peronistas a partir de 1973. En esa línea de convergencia entre nacionalismo y peronismo, el MNA se reconocía heredero de Eva Perón y de la ALN, ya que tanto la primera dama como el grupo nacionalista habían percibido la necesidad de formar una milicia en tiempos del peronismo clásico. Sin lugar en su estructura tradicional, la milicia revolucionaria no podía compararse a las demás ramas del movimiento, puesto que escapaba a la legalidad del régimen, algo que no sucedería con la Juventud Peronista, las 62 organizaciones sindicales y el Partido Justicialista. Por esta razón, solo la milicia podía revolucionar al movimiento, posición en sintonía con aquella tendencia creciente de diversos sectores políticos e intelectuales que veían al peronismo como una revolución inconclusa.

La milicia era necesaria "para alumbrar al Movimiento con el incendio, para despertar al dormido con el látigo, y lanzarlo al asalto heroico de la trinchera enemiga". ${ }^{37}$ Esta idea de vanguardia, totalmente desprovista de connotaciones clasistas, se relaciona no tanto con la teoría leninista de la organización, sino más bien con su tradicional acepción militar, como destacamento de avanzada de un ejército regular. Sintomáticamente, en el conocido manual de conducción política redactado por Perón, hay una sola referencia a la noción de vanguardia, y aparece en el relato de una anécdota bélica (Perón, 1974: 15). Si atendemos al universo falangista en el cual se habían formado los militantes de Tacuara, los escritos de José Antonio Primo de Rivera emplearon el significante vanguardia con un significado puramente militar, pero también en clave política como motor autónomo de la Revolución Nacional, en respuesta a las denuncias de que la Falange era un mero grupo de choque al servicio de las clases dominantes. ${ }^{38}$ Como señaló oportunamente Quentin Skinner, el lenguaje tiene una función básica de comunicar información, pero también sirve para trazar fronteras de inclusión y exclusión (desde el punto de vista del MNA, la Juventud Peronista no era una organización revolucionaria, así como los comunistas y los judíos eran una amenaza foránea). Desmenuzar el significado del concepto de vanguardia para estos militantes requiere entonces analizar las relaciones entre los conceptos del discurso emeneista y redes de creencias más amplias, hacia atrás en el tiempo y de manera lateral con el Movimiento Nacionalista Revolucionario Tacuara, la última deriva de la organización liderada por Ezcurra Uriburu (Skinner, 2007: 32-33).

37 "La función de la milicia" (s/f), cit., p. 2.

38 Primo de Rivera, José Antonio Obras completas (s/ref.), pp. 199-335-417-459-488-489-550-568569-631-699. Disponible en URL: www.rumbos.net/ocja/ 


\section{La Tacuara revolucionaria y la vanguardia de clase}

La revolución nacional socialista del MNRT se distinguía de la nacional sindicalista de Tacuara y la nacional justicialista del MNA no solo por su adjetivación, sino también por sus actores. Como consignaba el lema que aparecía en la prensa oficial de la Tacuara revolucionaria, "Del proletariado y la clase media con Conciencia Nacional y Social, surgirán los soldados del ejército de Liberación Nacional que gestará la Revolución Nacional y Socialista". ${ }^{39}$ Desde el principio, el MNRT procuró diferenciarse del "viejo nacionalismo" racialista y católico que caracterizaba a la primigenia Tacuara. En una entrevista brindada a Primera Plana, Joe Baxter sostenía: "Nos sacamos de encima a toda la Segunda Guerra Mundial, ya no nos consideramos derrotados en la batalla de Berlín y empezamos un nuevo camino". ${ }^{40}$ Uno de los indicios del giro izquierdista del MNRT era el lugar que se asignaba a la clase obrera en el proceso revolucionario:

“El proletariado es la única clase del país que tiene Conciencia Nacional y su permanente militancia antioligárquica y antiimperialista lo convierten en motor de la Revolución Nacional [...] su condición de clase oprimida le ha dado una mayor conciencia del cambio radical que es necesario realizar en las estructuras económico-sociales." ${ }^{41}$

Esta lectura marxista, donde los actores sociales se organizan de manera agonal según el rol que tienen asignado en el proceso de producción, significó una ruptura con el discurso tacuarista tradicional, que rara vez utilizaba términos como proletariado y lucha de clases. Para Julio Ríos, el ascenso de Perón en 1943 había permitido que el "proletariado nacional de origen provinciano" se incorpore a la vida gremial y política del país. Por esta razón, el peronismo era caracterizado como un movimiento nacional revolucionario, aunque con reservas:

"Su acción se ve frenada por el aburguesamiento de un sector importante -por los resortes que tiene en su poder- de dirigentes. La primera contradicción surge al observar la antinomia entre su capa "oficial" de representantes: burocratizada y reformista y los cuadros dirigentes de su juventud: rebelde y combatiente. El entronque de la minoría conductora con Conciencia Revolucionaria, que haga de puente entre el pueblo y su Líder, no puede esperar más." ${ }^{42}$

\footnotetext{
39 Tacuara del manchón, n.1 (octubre de 1963), p. 1.

40 "Variante: una Tacuara izquierdista”, en Primera Plana, núm.55 (26/09/63).

41 Baxter, José Joe (octubre 1963). “Tacuara y la liberación nacional”, en Tacuara del manchón, núm.1, p. 4.

42 Ríos, Julio (octubre 1963). “Tacuara y la liberación nacional”, en Tacuara del manchón, núm. 1,
} 
Tal valoración crítica coincidía en varios aspectos con los argumentos de peronistas de izquierda como John William Cooke, Mario Valotta y Gustavo Rearte, que cuestionaban la burocratización de la dirigencia peronista, y apostaban a construir una vanguardia revolucionaria dentro del movimiento. ${ }^{43}$ Pero también, en la referencia emenerretista de las minorías conductoras resonaban los ecos de aquel nacionalismo de masas pasivas y líderes proteicos, reivindicado por la Tacuara nacionalista. La diferencia entre el viejo nacionalismo del MNT y la novedad que significaría el MNRT, era que el primero tenía que "dejar de lado sus prejuicios de élite", mientras que el segundo debía converger con los cuadros juveniles del peronismo duro. Si el nacionalismo no se apoyaba en el pueblo, solo le restaba convertirse en fuerza de choque de la burguesía: "La disyuntiva es clara, o somos la Conciencia y la Vanguardia del Gran Movimiento Popular de Liberación Nacional o pasamos a ser la anestesia de la Revolución Nacional". ${ }^{44}$ En otra nota llamada "Tacuara y el Movimiento Nacional", se repiten los conceptos vertidos sobre el peronismo, con el añadido de incluir a los trabajadores y "la eclosión popular ocurrida en 1945", en una larga saga de combates entre la patria y la antipatria, el pueblo y la oligarquía, que se remontaba a la época de las guerras civiles argentinas. ${ }^{45}$ Una definición arraigada en el revisionismo histórico, donde Perón era el jefe del movimiento nacional, y el nacionalismo su doctrina revolucionaria, si bien el peronismo todavía no era apto como herramienta para llevar adelante las tareas de la liberación nacional y social:

“Evidentemente falta la minoría dirigente capaz de organizar el Movimiento para su función revolucionaria y racionalizar la intuitiva Conciencia Revolucionaria que tiene el pueblo peronista. No es que falten elementos capaces dentro de él, sino que estos ven frenada su acción por los elementos reformistas y traidores, que pretenden frustrar al Movimiento, tratándolo de encuadrarlo en el régimen, convirtiéndolo en un partido burgués más." 46

\footnotetext{
p. 4.

43 "Reportaje a John William Cooke desde La Habana" (septiembre de 1961); Cooke, John William (28/09/61) "Carta a Juan José Hernández Arregui"; "Carta a dos compañeros de FOETRA (fines de 1964); Valotta, Mario (agosto 1963) "Nuevo punto de partida", Rearte, Gustavo (noviembre 1964) "Es la hora de las definiciones" (Baschetti, 1997: 186-194, 198-203, 256-257, 327-329, 347-349); Cooke, John William (octubre-noviembre 1966) "Peronismo revolucionario", en Cristianismo y Revolución, núm. 2-3; "Programa del Movimiento Revolucionario Peronista" (abril 1968), en Cristianismo y Revolución, núm. 6-7, pp. 14-15.

${ }^{44}$ Ríos, Julio (octubre 1963). “Tacuara...", cit., p. 4.

45 “Tacuara y el Movimiento Nacional” (s/f), Tacuara del manchón, núm.3 (noviembre de 1963), p. 3.

46 "Tacuara y el Movimiento Nacional" (s/f), Tacuara del manchón, núm.3 (noviembre de 1963), p. 3.
} 
La solución era promover a los cuadros juveniles en la dirección del peronismo, ya que estos tendrían la capacidad para elevar su nivel de conciencia y organizar la acción revolucionaria. Así se articularía la "trilogía necesaria para la Liberación Nacional: fuerzas sociales aptas, con una doctrina revolucionaria, encuadrados en un Movimiento operante". El MNRT se sentía parte del peronismo por compartir la doctrina nacionalista revolucionaria y los objetivos de liberación nacional, pero intentaba preservar su identidad como grupo separado, ya que creía necesario defender su "individualidad en cuanto a organización, jerarquías y métodos de acción". Como el MNT, la Tacuara revolucionaria quería llevar al peronismo hacia posiciones revolucionarias barriendo a sus estamentos burocráticos, pero a diferencia del MNA, las declaraciones más entusiastas de lealtad al liderazgo de Perón ocupaban un lugar claramente marginal en comparación con la argumentación sobre la necesidad de una vanguardia.

En septiembre de 1964, el periodista y militante peronista Pedro Leopoldo Barraza, entrevistó para el semanario Compañero a varios militantes del MNRT encarcelados por el asalto al Policlinico Bancario. Lo notable de este reportaje, en comparación a los tres números de Tacuara del manchón publicados entre octubre y noviembre de 1963, es la plena adopción del vocabulario marxista para analizar a la sociedad argentina y al movimiento peronista. Desde la óptica de los presos emenerretistas, "la dinámica de las clases sociales que participan en esta realidad, no es nada más ni nada menos que esa lucha a muerte de fuerzas fatalmente antagónicas" 47 En la definición sobre el peronismo se hacía más patente la convergencia entre lo que quedaba del sector BaxterNell del MNRT y las caracterizaciones del peronismo revolucionario:

“¿Qué pasa con el peronismo? [...] ¿Asistimos al entierro de la burocracia?

MNRT: Mal que les pese a los teóricos idealistas, que no contemplan la composición de clases en el Movimiento Nacional, son sus clases las que determinan su desarrollo [...] Como revolucionarios, es decir, como protagonistas conscientes del proceso, observamos que el Movimiento Nacional está atravesando el desenlace de su contradicción interna: el enfrentamiento de la burocracia -expresión de un frente histórico que ha agotado sus posibilidades de vida- con la clase trabajadora. Contradicción que se resuelve en la medida que la clase trabajadora se da su propia organización revolucionaria." 48

\footnotetext{
47 Guay, Martín (08/09/64) "Reportaje al Movimiento Nacionalista Revolucionario Tacuara", en Compañero núm. 63. El subrayado en cursiva figura en el original. El nombre Martín Guay era un pseudónimo utilizado por Pedro Leopoldo Barraza.

${ }^{48}$ Guay, Martín (08/09/64) "Reportaje al Movimiento...".
} 
La nota en general exhibe un lenguaje muy parecido al desarrollado por Mario Valotta en Compañero y por la Juventud Revolucionaria Peronista de Gustavo Rearte, ya que insistía en la existencia de una línea revolucionaria dentro del peronismo (Raimundo, 2001). En sintonía con estas posiciones, la reivindicación que hacía el MNRT en su prensa de una minoría conductora, que debía provenir de las filas juveniles del peronismo, cedía espacio a la propuesta de que los trabajadores construyan su propia organización revolucionaria. Por otra parte, para los presos emenerretistas Perón era un caudillo de carne y hueso, un "hombre-jefe", pero a la vez constituía un "hombre-símbolo". En el primer peronismo alcanzaba con la faceta simbólica del líder, ya que la palabra de Perón al frente del Estado invocaba la movilización de los trabajadores, y realizaba las tareas de la organización revolucionaria. Sin embargo, el golpe militar de 1955 había abierto un nuevo escenario:

"Al variar las condiciones objetivas de nuestro país, presentando a la clase trabajadora como única vanguardia real frente a los demás sectores sociales no comprometidos con el sistema, la faz simbólica del caudillo es insuficiente para forjar el instrumento adecuado -la organización revolucionaria- que diferencie a los trabajadores del frente de clases libertario y que le permita conducirlo." 49

El agotamiento de la palabra de Perón en el exilio hacía posible la emergencia de una vanguardia de trabajadores peronistas. No obstante, los militantes del MNRT advertían que: “Perón no es bronce ni mármol, ni material de análisis para sociólogos apresurados; Perón es realidad viva y su mensaje es Revolución". ${ }^{50}$ A esta caracterización, tan parecida al diagnóstico elaborado por el MNA, se le agregaba un elemento que podría pasar desapercibido si no fuera por su amplia difusión una década más tarde como parte del discurso montonero: el MNRT sostenía que la burocracia había establecido un cerco en torno al líder para frenar el avance de la organización revolucionaria del peronismo.

En noviembre de 1964, los Centros Organizados Nacionales de Orientación Revolucionaria (C.O.N.D.O.R) y el MNRT publicaron de común acuerdo un cuadernillo titulado "El retorno de Perón (alienación y contrarrevolución de las 'izquierdas')". El escrito había surgido a partir de las conversaciones entre los abogados Rodolfo Ortega Peña y Eduardo Luis Duhalde con los presos del MNRT, a los que representaban en la causa del Policlínico Bancario. ${ }^{51} \mathrm{El}$ texto llevaba al extremo algunos de los conceptos sobre

${ }^{49}$ Guay, Martín (08/09/64). “Reportaje...”, cit. (s/pág.).

${ }^{50}$ Guay, Martín (08/09/64). “Reportaje...”, cit. (s/pág.).

51 C.O.N.D.O.R estaba integrado por intelectuales como Juan José Hernández Arregui, Ricardo Carpani y Alberto Belloni, entre otros. El texto habría sido redactado por Ortega Peña, aunque firmado por él y Duhalde en representación de los cóndores, y por Jorge Caffatti y Pedro 
el peronismo desarrollados por la entrevista de Compañero, pero también deconstruía otros que se remontaban a la ruptura con la Tacuara nacionalista en 1963. Para C.O.N.D.O.R y el MNRT, el peronismo era "un movimiento nacional de masas, que está desarrollando su propia vanguardia revolucionaria, surgida en su seno" ${ }^{52}$ El corolario de este razonamiento era que cualquier intento de construir una vanguardia por fuera del peronismo estaba condenado al aislamiento y el fracaso. A diferencia de las definiciones vertidas en Tacuara del manchón un año atrás, donde la minoría dirigente debía racionalizar la intuitiva conciencia revolucionaria del pueblo peronista, en el documento aprobado por el MNRT se sostenía que "La espontaneidad de las masas, que nunca ha sido ciega, en la República Argentina, ha sido y es revolucionaria". ${ }^{53}$ En esta nueva elaboración, Perón era "una categoría histórica dinámica, que da dirección a ese proceso, lo unifica, y es el resultado de esa 'espontaneidad' dirigida". ${ }^{54}$ La caracterización es llamativa, porque aquí la figura del líder ya no está desdoblada en una dimensión simbólica y una material, sino que aparece sintetizada como una "categoría histórica", que en su eficacia sobre el proceso político concreto se parece al Perón-mito o al Perón-nombre denostado por las plumas del MNT. De manera coincidente con las historiografías de la izquierda nacional y la izquierda peronista, el liderazgo de Perón era la consecuencia de procesos sociohistóricos que lo excedían (Acha, 2009: 203-248; 301-338).

Finalmente, la crítica de la teoría leninista de la vanguardia llevaba a C.O.N.D.O.R y al MNRT a posiciones lindantes con la teoría de la organizaciónproceso del luxemburguismo, tal como había ocurrido en el pasado con el MNT: "Para que exista una 'vanguardia revolucionaria', debe darse una madurez tal en el proceso, que la revolución esté en plena etapa de cumplimiento [...] Al no aceptar una conducción 'partidista', racional y teleológica, pero al servicio del imperialismo, las masas se mueven, expresándose en forma directa, sin mediaciones." 55 La vanguardia era la expresión de una clase social que aspiraba al poder y adquiría conciencia de sus

Leopoldo Barraza por el MNRT, (Eidelman, 2004: 34-43).

52 C.O.N.D.O.R-MNRT, “El retorno de Perón (Alienación y contrarrevolución de las 'izquierdas')" (Baschetti, 1997: 331-344).

53 C.O.N.D.O.R-MNRT "El retorno...", cit, p. 332. El órgano de prensa del sector Ossorio del MNRT tenía concepciones más cercanas al elitismo de la Tacuara nacionalista: una vez agotadas las experiencias del "nacionalismo bravucón" (el MNT) y el nacionalismo de "especulaciones metafísicas" (el de Marcelo Sánchez Sorondo y Mario Amadeo), "la experiencia peronista nos llamó a la realidad", dándole al nacionalismo una "doctrina absolutamente revolucionaria", v. R.B.B. (octubre de 1963) "En torno al nacionalismo", en Barricada núm.1, p. 2. Sin embargo, en otro artículo se cuestionaba a aquellos nacionalistas que "ponen sus esperanzas en las masas (que nunca han servido para nada: sólo las minorías operantes hacen historia", v. M. (noviembre de 1963) “¡Cuidado con la izquierda nacional!”, en Barricada núm. 2, p. 2.

54 C.O.N.D.O.R-MNRT “El retorno...", cit, p. 332.

55 C.O.N.D.O.R-MNRT “El retorno...", cit, p. 338. 
objetivos en el transcurso de la lucha misma. ${ }^{56}$ Sin embargo, ni C.O.N.D.O.R ni el MNRT aceptaban la necesidad de un partido revolucionario de clase, lo que diferenciaba sus ideas del cookismo y de las teorías marxistas de la organización en general. Las masas peronistas tenían la capacidad de darse su propia forma organizativa y saltar por encima de la burocracia, para presionar directamente al poder y obtener resultados revolucionarios. En última instancia, el vanguardismo del MNRT había derivado en un movimientismo basista que apostaba formalmente a la organización revolucionaria, pero no dejaba lugar para la construcción de una vanguardia entendida como el "sujeto-supuestosaber" de la revolución socialista, una mediación que ocupa el lugar de la Verdad entre la mirada parcial e incompleta de las masas, y la totalidad omnisciente del poder (Zizek, 2003: 39-42).

\section{Consideraciones finales}

El surgimiento de tendencias filoperonistas dentro de Tacuara fue una pequeña pero significativa mutación en la trayectoria del nacionalismo argentino. El estallido del campo político peronista en 1955, y la marginación de sus simpatizantes del Estado, los sindicatos y la esfera pública, facilitaron el crecimiento de organizaciones como el MNT, que captaron parte del activismo juvenil en varios colegios secundarios. Sin embargo, la rápida recomposición del peronismo sindical, el arraigo popular del liderazgo de Perón y la combatividad del movimiento proscripto generaron una situación revisionista en parte del campo nacionalista que afectó a Tacuara. La dirigencia del MNT consideró al peronismo como un movimiento de masas de orientación nacional, que podía ser ganado para la Revolución nacional-sindicalista si se lo separaba de sus capas dirigentes burocráticas, aunque no había acuerdo sobre el carácter de la ideología peronista y el papel de Perón: si para Ezcurra Uriburu el peronismo carecía de base doctrinaria y cuadros revolucionarios, para Oscar Denovi el peronismo tenía doctrina, militantes formados y un caudillo vigente. Otros columnistas, en cambio, sostenían que el liderazgo de Perón era un descolorido mito incapaz de frenar el avance comunista sobre el sindicalismo justicialista. La sucesión de estas diferentes posiciones expresaban la perplejidad de los dirigentes tacuaristas por la separación de varios militantes de la organización y su incorporación al movimiento peronista.

El Movimiento Nueva Argentina, si bien conservó varios tópicos tacuaristas como el antisemitismo y el anticomunismo, reivindicó la Revolución nacional-justicialista como una alternativa a las revoluciones internacionales de signo izquierdista. Por el contrario, el Movimiento Nacionalista Revolucionario Tacuara, principalmente el sector liderado por Joe Baxter y José Luis Nell,

56 Mandel, Ernst La teoría leninista de la organización (s/ref.), p. 12. Disponible en URL: https://www.ernestmandel.org/es/escritos/pdf/form teoria-leninista-organizacio.pdf 
abjuró del antisemitismo y se acercó a posiciones de izquierda, al reivindicar el socialismo y utilizar el marxismo como método de análisis. Una buena manera de pensar estos tránsitos y variaciones es resistir la tentación de distinguir una Tacuara "buena" de una "mala", una moderna y marxista que evolucionaría de otra tradicionalista y racista. Por el contrario, parece más conveniente comprender las rupturas y continuidades entre el MNT, el MNA y MNRT en su propia racionalidad política, incluso cuando portan contenidos antisemitas y anticomunistas que no forman parte de la subjetividad del investigador. Como señala Quentin Skinner, no hay errores de razonamiento que requieran una explicación adicional del historiador, ya que las creencias verdaderas son aquellas adecuadas a las circunstancias de la época en que los actores se encuentran (Skinner, 2007: 71-77). ${ }^{57}$

La caracterización del peronismo en Tacuara y sus agrupaciones derivadas se relacionaba a otros conceptos que tematizaban el papel dirigente de las organizaciones nacionalistas, como el de la vanguardia revolucionaria. El MNT tenía el objetivo de cooptar a las masas peronistas, para desplazar a la burocracia política y sindical del justicialismo en pos de la Revolución nacionalsindicalista, con una vanguardia que debía forjarse en la lucha misma. No obstante, una revisión atenta de Tacuara. Vocero de la juventud nacionalista y Ofensiva muestra que desde fines de 1962 había una perspectiva más sombría que daba cuenta del fenómeno contrario, la cooptación del tacuarismo por el peronismo. Estas lecturas surgieron después de que varios militantes del MNT participaran por su cuenta de la campaña del peronista Andrés Framini como candidato a gobernador de la provincia de Buenos Aires. En aquellos años, Tacuara se dividió por el impacto de una coyuntura donde el peronismo se convirtió nuevamente en un factor de poder, prestigiado por una aureola resistente y un arraigo popular que desafiaba la proscripción. También, las tendencias centrífugas estaban inscriptas en el propio desarrollo de las organizaciones nacionalistas desde los años '30 y '40, escindidas entre las tradiciones nacional-elitistas y nacional-populares, entre el sueño de construir una fuerza política propia y el seguidismo a las Fuerzas Armadas y el peronismo. En ese sentido, la suerte de Tacuara fue similar a la corrida por la ALN pero no fue la misma: el peronismo combativo e insular de los años '60, con las revoluciones tercermundistas como telón de fondo, era muy diferente a la utopía corporativa de los años '40, inspirada en el nacionalismo derechista de entreguerras. Hasta el MNA, que criticaba en sus documentos la infiltración del sionismo y el comunismo en la Argentina, tenía que sentar posición sobre la socialización de los medios de producción. El MNRT dio un paso más, y atravesó el umbral ideológico del nacionalismo de derecha para incluir conceptos marxistas en su discurso político.

57 La crítica a la tendencia de considerar al MNT una Tacuara "mala" y al MNRT una Tacuara "buena" es de Beraza, Luis (2005: 154). 
Para el Movimiento Nueva Argentina, la vanguardia revolucionaria debía someterse al liderazgo de Perón, que no era un mero símbolo, sino el único líder legítimo del movimiento peronista. Los militantes emeneístas decían ser el sector más dinámico y antisistémico del justicialismo, pero no se adjudicaban un papel dirigente al margen del caudillo, argumento que independientemente de su sinceridad, les permitía legitimar su peronicidad.58 El Movimiento Nacionalista Revolucionario Tacuara reconocía el liderazgo de Perón, pero exhibió notables cambios en su teoría de la vanguardia. Hacia 1963, la Tacuara revolucionaria sostuvo en su prensa que los dirigentes juveniles del peronismo debían aportar los cuadros capaces de dar forma a la conciencia intuitiva de las masas peronistas, una interpretación con raíces en las concepciones de la Tacuara nacionalista. Un año después, en cambio, los presos políticos del MNRT argumentaron que la clase trabajadora tenía que darse su propia organización revolucionaria, en sintonía con las ideas de Mario Valotta y Gustavo Rearte. El documento firmado por C.O.N.D.O.R. y el MNRT llevó al extremo estas premisas, al defender la espontaneidad de las masas peronistas como una forma de conciencia revolucionaria, y rechazar la teoría leninista de la vanguardia. En última instancia, a pesar de estas variaciones de mayor complejidad teórica, solo el MNA se liberó de la tensión implícita en las propuestas del MNT y el MNRT que significaba concebir una vanguardia revolucionaria en un movimiento conducido por un líder carismático. En los términos de Silvia Sigal y Eliseo Verón, que analizaron el caso de la Juventud Peronista, había una contradicción insoluble entre la pretensión de hablar en nombre del pueblo, y la subordinación a la palabra de Perón (Sigal y Verón, 1988: 136).

La lectura del peronismo como un movimiento necesitado de una vanguardia y un cuerpo doctrinario para alcanzar posiciones revolucionarias no era un invento de Tacuara. En 1953, el Partido Socialista de la Revolución Nacional se acercó a Perón para ofrecerle "un arma política adecuada con una ideología socialista" (Galasso, 1983: 80). Como hemos visto, John William Cooke veía al peronismo como un gigante invertebrado y miope, que precisaba de una dirección política y una teoría para convertir al movimiento justicialista en un partido revolucionario, al estilo de Lenin en el Que hacer? Por último, la Juventud Demócrata Cristiana definía al peronismo en 1964 como "una emoción nacional" que podía movilizar a las clases populares "con el estímulo de programa, de dirección y de oportunidad que necesita" (Castro y Salas, 2011: 119). La izquierda marxista no era la única cultura política que esperaba, al decir de Carlos Altamirano, la crisis o la transmutación del peronismo, dividiéndose en torno a la estrategia de operar desde dentro o fuera del movimiento para atraer a esas aparentes masas en disponibilidad, o para

58 El concepto de "peronicidad" para definir las formas de legitimación entre peronistas es de Garzón Rogé (Garzón Rogé, 2017). 
transformar al justicialismo en una síntesis revolucionaria (Altamirano, 2001: 64). La reunión de los dos cuerpos de Perón, el simbólico y el material, a partir de su retorno definitivo al país, acabó bruscamente con la ilusión de transmutar el peronismo en revolución. Tres años después, la crisis del peronismo tampoco condujo a una alternativa emancipatoria, sino a la dictadura militar y al terror estatal.

Buenos Aires, marzo de 2019

\section{Bibliografía citada}

Acha, Omar (2009). Historia crítica de la historiografía argentina (vol. 1: Las izquierdas en el siglo XX), Buenos Aires: Prometeo.

Altamirano, Carlos (2001). Peronismo y cultura de izquierda, Buenos Aires: Temas Grupo Editorial.

Bardini, Roberto (2002). Tacuara. La pólvora y la sangre, México: Océano.

Baschetti, Roberto (1997). Documentos de la resistencia peronista, La Plata: De la Campana

Beraza, Luis Fernando (2005). Nacionalistas. La trayectoria política de un grupo polémico (1927-1983), Buenos Aires: Cántaro.

Besoky, Juan Luis (2016). La derecha peronista. Prácticas políticas y representaciones (1943-1976), La Plata: tesis doctoral en Ciencias Sociales, UNLP.

Campos, Esteban (en prensa). "La prensa del Movimiento Nacionalista Revolucionario Tacuara en las mutaciones del nacionalismo argentino", en Folia Histórica del Nordeste, núm. 34.

Castro, Flora y Salas, Ernesto (2011). Norberto Habegger. Cristiano, descamisado, montonero, Buenos Aires: Colihue.

Eidelman, Ariel (2004). Militancia e historia en el peronismo revolucionario de los años 60: Ortega Peña y Duhalde, Buenos Aires: Centro Cultural de la Cooperación, Cuaderno de Trabajo núm. 31.

Furman, Rubén (2014). Puños y pistolas. La extraña historia de la Alianza Libertadora Nacionalista, el grupo de choque de Perón, Buenos Aires: Sudamericana.

Galasso, Norberto (1983). La izquierda nacional y el FIP, Buenos Aires: CEAL.

Galván, Valeria (mayo 2013). “Militancia nacionalista en la era postperonista: las organizaciones Tacuara y su vínculo con el peronismo", en Nuevo Mundo Mundos Nuevos (en línea) Cuestiones del tiempo presente. URL: https://journals.openedition.org/nuevomundo/65364 
Garzón Rogé, Mariana (2017). “Un espécimen peronista. Pruebas de identidad y modos prácticos de ser en el primer peronismo", en Pilquén, Sección Ciencias Sociales, Vol. 20, núm. 4, pp. 82-95.

Glück, Mario (2012). “Una batalla de una guerra imaginaria: Tacuara, el Partido Comunista y el gremialismo en el plenario sindical de febrero de 1964 en Rosario", en Entrepasados, Año XX, núm. 38-39, pp. 37-58.

Goebel, Michael (marzo 2007). “A Movement from Right to Left in Argentine Nationalism? The Alianza Libertadora Nacionalista and Tacuara as Stages of Militancy, en Bulletin of Latin American Research, núm. 26/3, pp. 356-377.

Gutman, Daniel (2003). Tacuara. Historia de la primera guerrilla urbana argentina, Buenos Aires: Vergara.

Lvovich, Daniel (2006). El nacionalismo de derecha. Desde sus orígenes a Tacuara, Buenos Aires: Capital Intelectual.

Lvovich, Daniel (2009). "La extrema derecha en la Argentina posperonista entre la sacristía y la revolución: el caso de Tacuara", en Diálogos. Revista do Departamento de História e do Programa de Pós-graduação em História, núm. 13/1 (Maringa).

Padrón, Juan Manuel (2017). ¡Ni yankis ni marxistas! Nacionalistas. Nacionalismo, militancia y violencia política: el caso del Movimiento Nacionalista Tacuara en la Argentina, 1955-1966, La Plata-Los Polvorines: UNLP-UNGS.

Perón, Juan Domingo (1974). Conducción política. Con un apéndice de actualización doctrinaria, Buenos Aires: Secretaría Política de la Presidencia de la Nación.

Raimundo, Marcelo (2001). "Compañero y los orígenes del peronismo revolucionario", en Sociohistórica, núm. 8, pp. 203-226.

Ruffini, Martha (julio 2016). “Poder y violencia en Argentina durante la década de 1960. La trama del atentado al ex presidente Arturo Frondizi", en Nuevo Mundo Mundos Nuevos (en línea) Cuestiones del tiempo presente. URL: https://journals.openedition.org/nuevomundo/69324

Sigal, Silvia y Verón, Eliseo (1988). Perón o muerte. Los fundamentos discursivos del fenómeno peronista, Buenos Aires: Hyspamérica.

Skinner, Quentin (2007). Lenguaje, política e historia, Bernal: Universidad Nacional de Quilmes.

Sternhell, Zeev, Snajder, Mario, Asheri, Maia (1994). The birth of fascist ideology. From cultural rebellion to political revolution, New Jersey: Princeton University Press.

Zizek, Slavoj (2003). A propósito de Lenin. Política y subjetividad en el capitalismo tardío, Bueos Aires: Atuel. 
